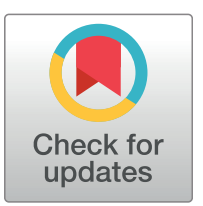

\section{G OPEnACCESS}

Citation: Rubina K, Shmakova A, Shabanov A, Andreev Y, Borovkova N, Kulabukhov V, et al. (2022) Novel prognostic determinants of COVID19-related mortality: A pilot study on severely-ill patients in Russia. PLoS ONE 17(2): e0264072. https://doi.org/10.1371/journal.pone.0264072

Editor: Jennifer A. Hirst, University of Oxford, UNITED KINGDOM

Received: June 10, 2021

Accepted: February 2, 2022

Published: February 25, 2022

Peer Review History: PLOS recognizes the benefits of transparency in the peer review process; therefore, we enable the publication of all of the content of peer review and author responses alongside final, published articles. The editorial history of this article is available here: https://doi.org/10.1371/journal.pone.0264072

Copyright: @ 2022 Rubina et al. This is an open access article distributed under the terms of the Creative Commons Attribution License, which permits unrestricted use, distribution, and reproduction in any medium, provided the original author and source are credited.

Data Availability Statement: The full data table with all the clinical and biochemical anonymous results is available from the OSF database DOI: 10.

RESEARCH ARTICLE

\title{
Novel prognostic determinants of COVID-19- related mortality: A pilot study on severely-ill patients in Russia
}

\author{
Kseniya Rubina $\oplus^{1 *}$, Anna Shmakova ${ }^{2}$, Aslan Shabanov ${ }^{3}$, Yulii Andreev ${ }^{3}$, \\ Natalia Borovkova ${ }^{3}$, Vladimir Kulabukhov ${ }^{3}$, Anatoliy Evseev ${ }^{3}$, Konstantin Popugaev ${ }^{3}$, \\ Sergey Petrikov ${ }^{3}$, Ekaterina Semina ${ }_{(}^{2,4}$
}

1 Laboratory of Morphogenesis and Tissue Reparation, Faculty of Medicine, Lomonosov Moscow State University, Moscow, Russia, 2 Laboratory of Molecular Endocrinology, Institute of Experimental Cardiology, Federal State Budgetary Organization National Cardiology Research Center Ministry of Health of the Russian Federation, Moscow, Russia, 3 Department of Intensive Care, Sklifosovsky Research Institute of Emergency Medicine of the Moscow Healthcare Department, Moscow, Russia, 4 Department of Biochemistry and Molecular Medicine, Faculty of Medicine, Lomonosov Moscow State University, Moscow, Russia

* kseniiarubina1971@gmail.com

\section{Abstract}

COVID-19 pandemic has posed a severe healthcare challenge calling for an integrated approach in determining the clues for early non-invasive diagnostics of the potentially severe cases and efficient patient stratification. Here we analyze the clinical, laboratory and CT scan characteristics associated with high risk of COVID-19-related death outcome in the cohort of severely-ill patients in Russia. The data obtained reveal that elevated dead lymphocyte counts, decreased early apoptotic lymphocytes, decreased CD14+/HLA-Dr+ monocytes, increased expression of JNK in PBMCs, elevated IL-17 and decreased PAI-1 serum levels are associated with a high risk of COVID-19-related mortality thus suggesting them to be new prognostic factors. This set of determinants could be used as early predictors of potentially severe course of COVID-19 for trials of prevention or timely treatment.

\section{Introduction}

The ongoing wave of COVID-19 infections resulting from an outbreak, which initially started in Wuhan in China, has reached alarming proportions across the globe, as reported by the World Health Organization (WHO) [1]. As of today, no specific antiviral treatment is available for COVID-19. The unprecedented challenge with SARS-CoV-2 infection calls for an integrated approach, encompassing the development of effective vaccines to prevent the spread of the disease, search for new drugs aimed at lowering the viral load and preventing the complications, and quest for the clues to early diagnostics of a severe course of the disease.

The clinical spectrum of COVID-19 manifestations appears to be remarkably wide, ranging from asymptomatic infection, mild upper respiratory tract illness to severe viral pneumonia with respiratory failure, systemic inflammation and immune dysregulation termed "cytokine storm", disseminated intravascular coagulation, multiorgan failure and even death [2-4]. 
17605/OSF.IO/TZN89 (https://osf.io/tzn89/?view_ only=2c70847e06a34fb0bffb9f61246c60db).

Funding: The reported study was funded by Russian Foundation for Basic Research (https:// www.rfbr.ru/rffi/eng) according to the research project 20-24-60029. The funders had no role in study design, data collection and analysis, decision to publish, or preparation of the manuscript.

Competing interests: The authors have declared that no competing interests exist.
Older age, diabetes and cardiovascular comorbidities are among the highest risk factors influencing the disease severity and the clinical outcome of SARS-CoV-2 infection $[4,5]$. However, severe COVID-19 has been registered not only in elderly patients or patients suffering from comorbidities, but also in apparently healthy young people $[6,7]$. The development of new prognostic algorithms for differential diagnostics to predict and reduce the severity and complications of COVID-19 remains essential.

The data obtained in the present study reveal novel prognostic factors associated with high risk of COVID-19-related death overtime in patients with severe COVID-19. These include: the elevated dead lymphocyte counts, decreased early apoptosis of lymphocytes, decreased CD14+, HLA-Dr+ (human leukocyte antigen D related) monocytes, increased JNK (c-Jun Nterminal kinase) expression in PBMCs (peripheral blood mononuclear cell), increased IL-17 and decreased PAI-1 (plasminogen activator inhibitor-1) serum level. The prognostic value of each determinant can potentially impact decision-making on the level of healthcare and require more extensive follow-up strategies.

To the best our knowledge this is the first integrated study based on the Russian population aimed to reveal the original prognostic COVID-19-related death factors.

\section{Materials and methods}

\section{Study design and clinical workflow}

The present study was a single-center retrospective study carried out on a cohort of $52 \mathrm{symp-}$ tomatic adult patients with the confirmed SARS-CoV-2 infection, admitted to intensive care unit (ICU) of N.V. Sklifosovsky Research Institute for Emergency Medicine, Moscow from April to July 2020. Reasons for ICU admission included the functional state deterioration with symptoms such as fever, cough, sore throat, signs of pneumonia and respiratory distress in case a patient had been hospitalized from home (51 patients) or transferred from another hospital (1 patient).

Demographic, clinical, and laboratory data were recorded at admission. The study was approved by the ethics committee of Sklifosovsky Research Institute of Emergency Medicine of the Moscow Healthcare Department (protocol \#5-120, issued on 01.04.2020). The need for written patient consent was waived by the ethics committee of the hospital because laboratory investigations were conducted according to the local standard. The local ethical committee approved the retrospective study.

Nasopharyngeal swabs were collected from all patients, followed by RT-PCR assay to confirm the SARS-CoV-2 infection. Philips Ingenuity Core 128 CT Scanner (Netherlands) was used for all examinations. In all cases, semi-quantitative CT scoring (severity ranging from 0 to 4) was evaluated according to the protocol recommended by Moscow Healthcare Department adapted from the International Protocols and enriched with local experience [8]. The applied treatments included antibiotics (azithromycin, imipenem/cilastatin, ceftriaxone, ceftriaxone/sulbactame, meropenem/linezolid, levofloxacin, ertapenem, vancomycin), hydroxychloroquine, tocilizumab, convalescent plasma, antivirals (lopinavir, ritonavir, ganciclovir, ribavirin), antihypertensive, anticoagulation, analgesic, NSAID, antiulcer treatment, vitamins and minerals (Supradyn, ascorbic acid, thiamine). Routine blood tests were carried out for all patients and the following parameters were evaluated: white blood cells (WBC), lymphocytes, monocytes, neutrophil, red blood cell (RBC), platelet counts, levels of hemoglobin, serum total protein, albumins, globulins, bilirubin, urea, creatinine, alanine aminotransferase (ALT), aspartate aminotransferase (AST), lactate dehydrogenase (LDH), creatine kinase (CK), prothrombin, fibrinogen, D-dimer levels, activated partial thromboplastin time (APTT) and the international normalized ratio (INR). 


\section{Biochemical parameters analysis in blood serum and PBMCs}

In addition to blood tests routinely and periodically performed in hospital, we assessed the levels of plasminogen (PLG), plasminogen activator inhibitor 1 (PAI-1), IL-1 $\alpha$, IL-17, transforming growth factor beta (TGF $\beta$ ), tumor necrosis factor alpha (TNF $\alpha$ ), and adiponectin (ADP) in blood serum. Blood serum was collected and immediately frozen. Commercially available ELISA kits (SEA605Hu for ADP, SEA071Hu for IL-1 $\alpha$, SEA063Hu for IL-17, SEA532Hu for PAI-1, SEB236Hu for PLG, SEA124Hu for TGF $\beta$, and SEA133Hu for TNF $\alpha$ (Cloud-Clone Corp., Wuhan, Hubei) were used to evaluate the corresponding analytes according to the manufacturers' protocols. The 3,3', 5,5'-tetramethylbenzidine (TMB) was used as a chromogen and the maximum absorption wavelength of $450 \mathrm{~nm}$ was detected using a microplate reader Multiscan Ascent (Thermo Fisher). The experiments were performed in duplicate.

Whole blood specimens were collected into EDTA-containing tubes either directly labelled with antibodies or subjected to PBMC purification using Lympholyte-H (Cedarlane) density gradient centrifugation. Antibodies against the following surface markers were applied for whole blood sample labelling: CD95 (mouse monoclonal anti-hu CD95-FITC 1F-362-T100, EXBIO), CD14 (mouse monoclonal anti-hu CD14-PE Conjugated Antibody A07764, Beckman Coulter) and HLA-Dr (HLA-Dr-FITC Conjugated Antibody, IM1638U, Beckman Coulter). Isotypic non-immune IgG (IgG1 Mouse-FITC Isotype Control, A07795, Beckman Coulter) was used as a control. For lymphocyte death analysis, PBMCs were stained with antiCD45, Annexin V, 7AAD (mouse monoclonal anti-hu CD45-FITC Conjugated Antibody A07782 Beckman Coulter; Annexin V-FITC Kit-AAD Kit, IM3614, Beckman Coulter; 7-AAD Viability Dye A07704, Beckman Coulter). Labelled cells were analysed by flow cytometry with CYTOMICS FC500 flow cytometer (Beckman Coulter) and CXP software. Lymphocyte and monocyte populations were gated on FSC vs. SSC plot. The following parameters were assessed: the absolute number per $1 \mu \mathrm{l}$ and the percentage of dead lymphocytes (CD45 +/7AAD+), the percentage of early (Annexin $\mathrm{V}+/ 7 \mathrm{AAD}$ ) and late apoptotic (Annexin $\mathrm{V}$ +/7AAD+) lymphocytes as well as the percentage of CD95+ lymphocytes and HLA-Dr+ monocytes (CD14+/HLA-Dr+). The gating strategy is shown in S1 Fig.

PBMC lysates were prepared using protease inhibitor Gordox $®$, and the apoptotic marker expression, such as Akt, Bad, Bcl-2, Caspase-8, Caspase-9, JNK and p53 was evaluated using Milliplex@MAP (Early Apoptosis 7-plex Magnetic Bead Kit, cat\#48-660MAG) assay and Luminex® (USA). The values for each parameter are presented as Median Fluorescence Intensity (MFI). The experiments were performed in duplicate.

\section{Outcome and exposures}

The outcome used in the survival analysis in the current study was COVID-19-related death, defined on the basis of International Classification of Diseases 10 code U07.1 (COVID-19, virus identified), recorded as either a primary underlying or secondary cause of death.

With respect to potential risk factors assessed as exposures, we obtained data for sex, age, body mass index (BMI), tobacco smoking status, chest CT severity score (the worst CT imaging data per patient presented in Table 1). Patients were grouped by age as: younger than 40 years, $40-49$ years, $50-59$ years, 60-69 years, $70-79$ years, and 80 years or older. BMI was grouped as: less than 30 (no evidence of obesity), 30-34.9 (obese class I), 35-39.9 (obese class II), and $40 \mathrm{~kg} \cdot \mathrm{m}^{-2}$ or higher (obese class III). Tobacco smoking status was identified as smoker, non-smoker (not a current smoker), or missing data. Chest CT score was grouped as 1-2 or 3-4 based on semi-quantitative CT scoring (ranging from 0 to 4 ) evaluated according to the protocol recommended by Moscow Healthcare Department adapted from the International Protocols and enriched with local experience [8]. 
Table 1. Cohort description with COVID-19 deaths by patient characteristics.

\begin{tabular}{|c|c|c|c|c|}
\hline & All patients $(n=52)$ & Alive $(n=41)$ & Deaths $(n=11)$ & $P$ \\
\hline \multicolumn{5}{|c|}{ Sex } \\
\hline Male & $28(54 \%)$ & $23(56 \%)$ & $5(45 \%)$ & 0.5295 \\
\hline Female & $24(46 \%)$ & $18(44 \%)$ & $6(55 \%)$ & \\
\hline \multicolumn{5}{|c|}{ Age, years } \\
\hline $18-39$ & $3(6 \%)$ & $3(7 \%)$ & $0(0 \%)$ & 0.2451 \\
\hline $40-49$ & $8(15 \%)$ & $7(17 \%)$ & $1(9 \%)$ & \\
\hline $50-59$ & $12(23 \%)$ & $11(27 \%)$ & $1(9 \%)$ & \\
\hline $60-69$ & $11(21 \%)$ & $8(19 \%)$ & $3(27 \%)$ & \\
\hline $70-79$ & $7(13 \%)$ & $6(15 \%)$ & $1(9 \%)$ & \\
\hline $80+$ & $11(21 \%)$ & $6(15 \%)$ & $5(45 \%)$ & \\
\hline \multicolumn{5}{|c|}{ BMI, $\mathrm{kg} \cdot \mathrm{m}^{-2}$} \\
\hline$<30$ & $32(62 \%)$ & $25(61 \%)$ & $7(64 \%)$ & 0.7470 \\
\hline $30-34.9$ & $16(31 \%)$ & $12(29 \%)$ & $4(36 \%)$ & \\
\hline $35-39.9$ & $2(4 \%)$ & $2(5 \%)$ & $0(0 \%)$ & \\
\hline $40+$ & $2(4 \%)$ & $2(5 \%)$ & $0(0 \%)$ & \\
\hline \multicolumn{5}{|c|}{ Tobacco smoking status } \\
\hline Non-smoker & $41(79 \%)$ & $35(85 \%)$ & $6(55 \%)$ & 0.5597 \\
\hline Smoker & $2(4 \%)$ & $2(5 \%)$ & $0(0 \%)$ & \\
\hline Missing data & $9(17 \%)$ & $4(10 \%)$ & $5(45 \%)$ & \\
\hline \multicolumn{5}{|c|}{ Chest CT severity score (the worst CT imaging data per patient) } \\
\hline $0-2$ & $32(62 \%)$ & $30(73 \%)$ & $2(18 \%)$ & $0.0009^{* * *}$ \\
\hline $3-4$ & $20(38 \%)$ & $11(27 \%)$ & $9(82 \%)$ & \\
\hline \multicolumn{5}{|c|}{ Major treatment applied ${ }^{a}$} \\
\hline Azithromycin & $33(64 \%)$ & $27(66 \%)$ & $6(55 \%)$ & 0.4892 \\
\hline Other antibiotics & $23(44 \%)$ & $12(29 \%)$ & $11(90 \%)$ & $<0.0001^{* * * *}$ \\
\hline Hydroxychloroquine & $46(88 \%)$ & $38(93 \%)$ & $8(73 \%)$ & 0.0599 \\
\hline Tocilizumab & $14(27 \%)$ & $12(29 \%)$ & $2(18 \%)$ & 0.4617 \\
\hline Convalescent plasma & $17(33 \%)$ & $16(39 \%)$ & $1(9 \%)$ & 0.0602 \\
\hline Antivirals & $11(21 \%)$ & $11(27 \%)$ & $0(0 \%)$ & 0.0530 \\
\hline Vitamins + minerals & $38(73 \%)$ & $31(76 \%)$ & $7(64 \%)$ & 0.4266 \\
\hline Antihypertensive & $38(73 \%)$ & $31(76 \%)$ & $7(64 \%)$ & 0.4266 \\
\hline Anticoagulation & $49(94 \%)$ & $39(95 \%)$ & $10(82 \%)$ & 0.5946 \\
\hline Antiulcer & $43(83 \%)$ & $32(78 \%)$ & $11(100 \%)$ & 0.0875 \\
\hline \multicolumn{5}{|c|}{ Underlying comorbidities ${ }^{b}$} \\
\hline Hypertension & $28(54 \%)$ & $22(54 \%)$ & $6(55 \%)$ & 0.9582 \\
\hline Congestive heart failure & $8(15 \%)$ & $8(20 \%)$ & $0(0 \%)$ & 0.1112 \\
\hline Ischemic heart disease & $9(17 \%)$ & $7(17 \%)$ & $2(18 \%)$ & 0.1545 \\
\hline Chronic kidney disease & $4(8 \%)$ & $2(5 \%)$ & $2(18 \%)$ & 0.1415 \\
\hline Diabetes & $3(6 \%)$ & $3(7 \%)$ & $0(0 \%)$ & 0.3554 \\
\hline Malignancy & $5(10 \%)$ & $3(7 \%)$ & $2(18 \%)$ & 0.2778 \\
\hline Cerebrovascular disease & $4(8 \%)$ & $2(5 \%)$ & $2(18 \%)$ & 0.1415 \\
\hline \multicolumn{5}{|c|}{ Complications during hospital stay ${ }^{c}$} \\
\hline Hydrothorax & $6(12 \%)$ & $1(2 \%)$ & $5(45 \%)$ & $<0.0001^{* * * *}$ \\
\hline Intoxication, sepsis, multiple organ failure & $8(15 \%)$ & $0(0 \%)$ & $8(73 \%)$ & $<0.0001^{* * * *}$ \\
\hline
\end{tabular}


Table 1. (Continued)

\begin{tabular}{|c|c|c|c|c|}
\hline & All patients $(n=52)$ & Alive $(n=41)$ & Deaths $(n=11)$ & $P$ \\
\hline Acute respiratory distress syndrome & $4(8 \%)$ & $0(0 \%)$ & $4(36 \%)$ & $<0.0001^{* * * *}$ \\
\hline Hemorrhagic shock & $1(2 \%)$ & $0(0 \%)$ & $1(9 \%)$ & 0.0512 \\
\hline Acute myopericarditis & $1(2 \%)$ & $1(2 \%)$ & $0(0 \%)$ & 0.6054 \\
\hline Pseudomembranous colitis & $1(2 \%)$ & $1(2 \%)$ & $0(0 \%)$ & 0.6054 \\
\hline Deep vein thrombosis of the lower extremities & $3(6 \%)$ & $1(2 \%)$ & $2(18 \%)$ & $0.0468^{*}$ \\
\hline
\end{tabular}

Data are presented as $\mathrm{n}(\%) . \mathrm{BMI}=$ body mass index. $P$ values of $\chi^{2}$ test comparison of different factors between alive and deaths groups are provided.

*** $-P<0.001$

${ }^{* * * *}-P<0.0001$.

a $-P$ value provided for the comparison of each treatment $v s$ non-treatment.

${ }^{\mathrm{b}}-P$ value provided for the comparison of each comorbidity $v s$ no such comorbidity.

${ }^{c}-P$ value provided for the comparison of each complication $v s$ no such complication.

Routine blood test parameters were organized into three groups relying on the pre-specified reference range accepted in Moscow hospital laboratories, including the clinical laboratory of N.V. Sklifosovsky Research Institute for Emergency Medicine: lower, within the reference range or higher than the reference range. The accepted reference values of the blood tests parameters are presented in S1 Table. In case the data of several measurements were available, the mean of all measurements was calculated and used for subsequent analysis. To ensure an adequate repartition in the groups, the categorization of the biochemical parameters in the blood serum and leukocytes was performed basing on the pre-specified reference values provided by the manufacturer in the kit instructions, literature data and evaluation of the histogram distribution data. The cut-off values for biochemical serum and leukocyte parameters are presented in S2 Table.

\section{Statistical analysis}

Categorical variables are described as numbers and percentages. Continuous variables are reported as the median (interquartile range). The contribution of varioust factors to the difference between alive and non-survival groups were assessed using $\chi^{2}$ test. To identify risk factors associated with COVID-19-related death, a survival analysis of the outcome was performed: time was defined as the time from hospital admission to the end of a follow-up (hospital discharge or death) and the event defined as death or hospital discharge after recovery. The Kaplan-Meier method was used to analyze cumulative survival curves and their difference between the groups categorized by type of exposure compared by log-rank tests. Exposures with difference between the groups $P<0.05$ by log-rank tests were considered significant. We created univariable Cox proportional hazards survival analysis models for the evaluated parameters of each patient to test for their association with survival. We also created multivariable Cox proportional hazards survival analysis models to identify independent risk factors. Complete cases were considered. The inclusion of variables in the final models were based on the following criteria: 1) significance in Kaplan-Meier and/or univariable analyses; 2) association with survival according to the previous studies [9-14];3) clinical knowledge.

Considering the small size of the cohort and to avoid overfitting in the model, we created three separate final multivariable Cox models, with variables grouped as clinical characteristics and hematological results; clinical biochemical routine blood test results; laboratory blood findings. The data were analyzed in R studio v.1.2.5042 with the survival and survminer packages. 


\section{Results}

A total of 52 patients, aged 26-88, with confirmed SARS-CoV-2 infection were included in the study cohort (Table 1). The median age was 64 (54-76) years; the median body mass index (BMI) was $28.7(25.8-31.1) \mathrm{kg} \cdot \mathrm{m}^{-2} ; 28$ patients (54\%) were men. 1 patient was admitted to intensive care unit (ICU) with CT score $0 ; 13$ patients with CT score $1 ; 18$ patients with CT score $2 ; 13$ patients with CT score 3, and 4 patients with CT score 4 . Overall, 11 (21\%) patients died. The group of non-survival patients didn't differ significantly from alive patients by sex, age, BMI, tobacco smoking status as compared by $\chi^{2}$ test (Table 1 ). No difference has been detected in the applied treatment regimens, except a more frequent usage of additional antibiotic therapy in non-survival patients presumably due to their insensitivity to azithromycin, as well as no significant difference in the frequency of underlying comorbidities was noted (Table 1). Chest CT score was significantly worse in the group of non-survival patients $\left(P=0.0009, \chi^{2}\right.$ test). Patients from non-survival group had much more severe complications during hospital stay, including hydrothorax $\left(P<0.0001, \chi^{2}\right.$ test), intoxication, sepsis, multiple organ failure $\left(P<0.0001, \chi^{2}\right.$ test), acute respiratory distress syndrome $\left(P<0.0001, \chi^{2}\right.$ test) (Table 1$)$.

To identify prognostic determinants of COVID-19-related mortality, the survival analysis was performed with time defined as a period from hospital admission to the end of the followup (hospital discharge or death) and event defined as death or hospital discharge after recovery (Fig 1). The Kaplan-Meier survival function analysis revealed that 20-day survival probability

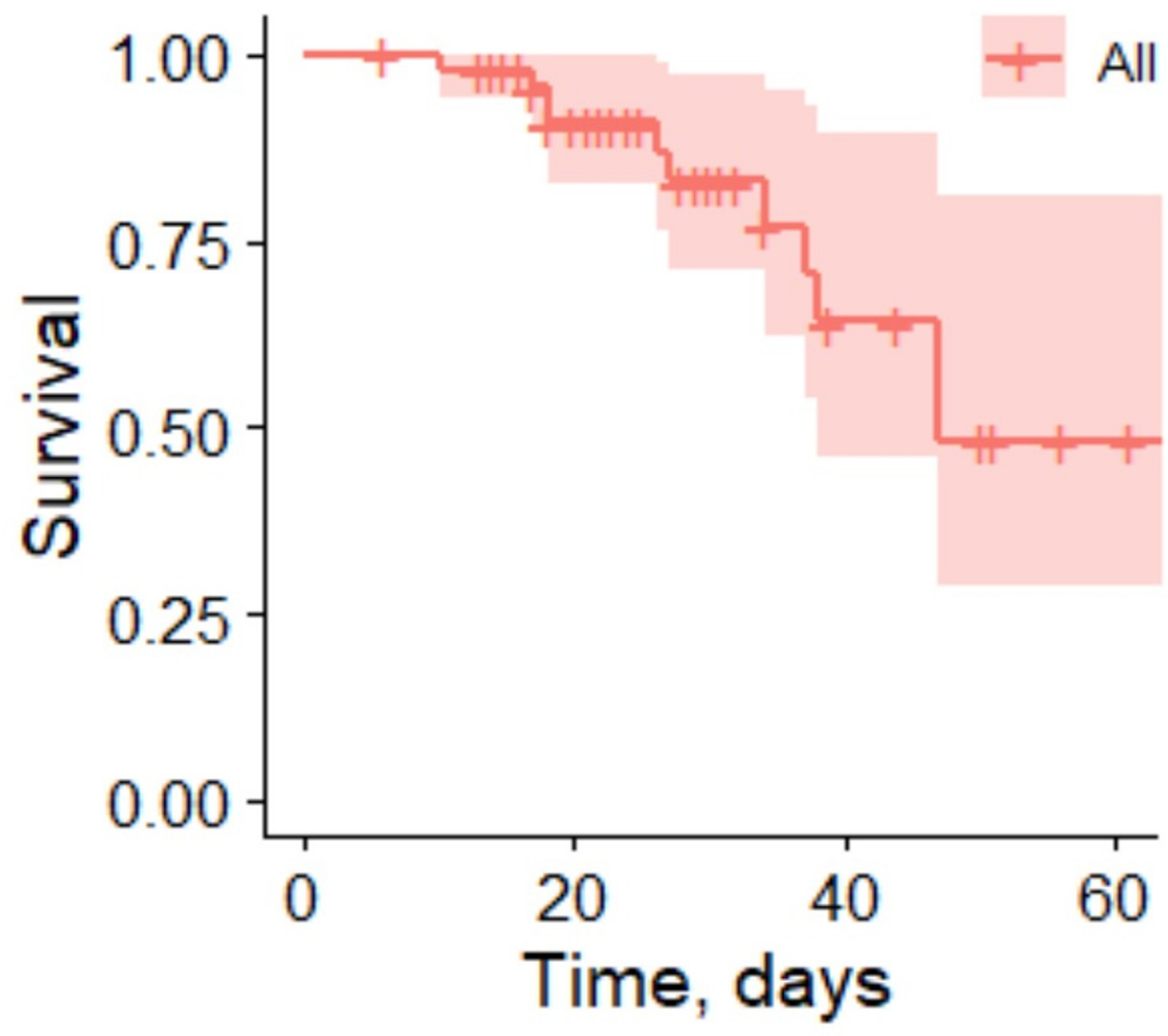

Fig 1. Kaplan-Meier survival curve with associated $95 \%$ confidence intervals (shaded area) for patients admitted with COVID-19 infection to ICU of N.V. Sklifosovsky Research Institute for Emergency Medicine, Moscow from April to July 2020. The fraction of survival is expressed on the y-axis, while time (days) of the observation period is expressed on the $\mathrm{x}$-axis. Vertical traits indicate censored data (hospital discharge).

https://doi.org/10.1371/journal.pone.0264072.g001 
was 91.0\% (95\% CI 82.9-99.9\%), 40-day survival probability was 64.3\% (95\% CI 46.1-89.5), 60-day survival probability was $48.2 \%$ (95\% CI $28.7-81.0 \%$ ).

We performed the Kaplan-Meier analysis to compare the survival over time between different groups of patients for each variable. The Kaplan-Meier survival plots for the clinical and routine blood test factors with statistically significant results are presented in Fig 2. We found, that the risk of COVID-19-related death over time was significantly increased in patients with CT score 3-4 at admission $(P=0.042)$, patients on pulmonary ventilation $(P=0.00047)$, patients with white blood cell (WBC) count more than $11.8 \cdot 10^{3} / \mu \mathrm{l}(P=0.001)$, neutrophil count more than $8.2 \cdot 10^{3} / \mu \mathrm{l}(P=0.00027)$, lymphocyte count less than $1.1 \cdot 10^{3} / \mu \mathrm{l}(P=0.018)$, increased serum levels of globulins more than $30 \mathrm{~g} / \mathrm{l}(P=0.046)$, urea more than $7.2 \mathrm{mM}$ $(P=0.01)$, creatine kinase $(\mathrm{CK})$ more than $200 \mathrm{U} / \mathrm{l}(P=0.023)$, prothrombin less than $78 \%$ $(P=0.023)$, the international normalized ratio (INR) more than $1.17(P=0.02)$ and D-dimer more than $2 \mathrm{mg} / \mathrm{l}(P=0.0078)$. Gender, age, BMI, tobacco smoking status and other parameters of routine blood tests were not associated with statistically significant differences as revealed by Kaplan-Meier analysis (S2 Fig).

The Kaplan-Meier survival plots for the biochemical test factors being statistically significant are presented in Fig 3. We found, that the risk of COVID-19-related death over time was significantly increased in patients with more than 100 dead lymphocytes in $1 \mu \mathrm{l}(P=0.0026)$, less than $5 \%$ of early apoptotic lymphocytes $(P=0.0081)$, less than $85 \%$ of CD14+/HLA-Dr + monocytes $(P=0.029)$, increased expression of JNK in PBMCs ( $>200$ MFI, $P=0.034)$, increased serum levels of IL-17 ( $>7 \mathrm{pg} / \mathrm{ml}, P=0.037)$ and decreased PAI-1 serum levels $(<40$ $\mathrm{pg} / \mathrm{ml}, P=0.00073$ ). Percentage of dead and late apoptotic lymphocytes, percentage of CD95 + lymphocytes, expression of Akt, Bad, Bcl-2, Caspase-8, Caspase-9, p53 and serum levels of plasminogen (PLG), IL-1 $\alpha$, TGF $\beta$, TNF $\alpha$, adiponectin (ADP) were not associated with statistically significant differences in survival as revealed by Kaplan-Meier analysis (S3 Fig).

To identify the independent risk factors, we created multivariable Cox proportional hazards survival analysis models separately for clinical characteristics and hematology results; for clinical biochemical routine blood test results and for laboratory blood findings (Table 2). On multivariable Cox proportional hazards survival analysis of clinical and routine hematological test parameters, ventilation (hazard ratio, HR $55.66(2.2-1388.4), P=0.014)$ and platelet count (HR 1.01 (1.002-1.027), $P=0.017)$ were found to be the independent prognostic factor for COVID-19 related death. On multivariable analysis of clinical biochemical routine blood test results, the serum levels of globulins (HR $1.32(1.03-1.70), P=0.026)$, CK (HR 1.02 (1.005$1.04), P=0.013)$ and $\mathrm{D}$-dimer (3.41 (1.11-10.50), $P=0.033)$ were found to be the independent prognostic factor for COVID-19 related death. On multivariable analysis of laboratory blood findings, the serum level of IL-17 (HR 1.07 (1.001-1.14), $P=0.046)$ and PAI-1 (HR 0.82 (0.69$0.98), P=0.026)$ were found to be the independent prognostic factor for COVID-19 related death. The results of univariable Cox proportional hazards survival analysis for each parameter are presented in \$3 Table.

\section{Discussion}

With the rapid spread of COVID-19 around the world since its outbreak in early 2020, it has stirred up an international concern and still remains so. Moreover, the poor survival rates of high-risk patients warrant investigation into novel prognostic factors implicated in COVID-19 pathogenesis, as well as diagnostic and treatment options aiming to reduce COVID-19-related burden in healthcare system. To address this question, we carried out a single-center cohort study on 52 symptomatic adult patients with the confirmed SARS-CoV-2 infection, admitted to ICU of N.V. Sklifosovsky Research Institute for Emergency Medicine, Moscow from April 


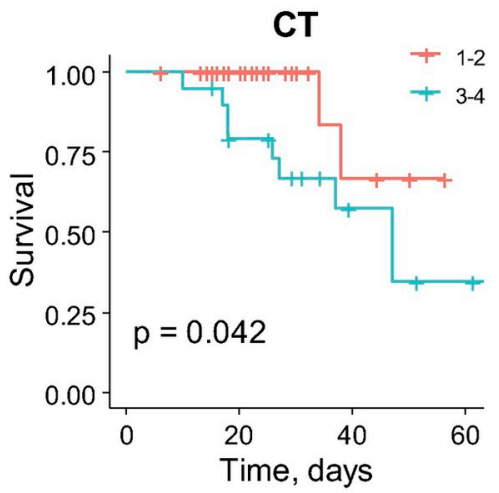

Neutrophil count

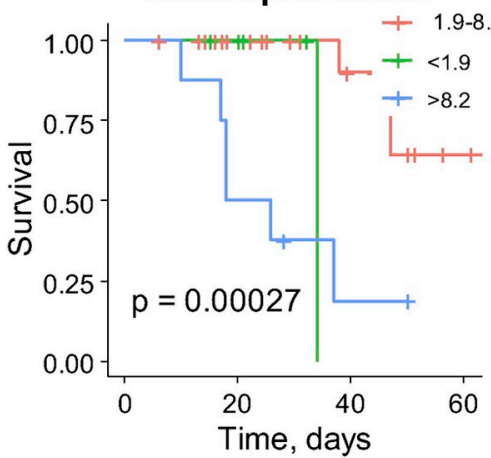

Urea

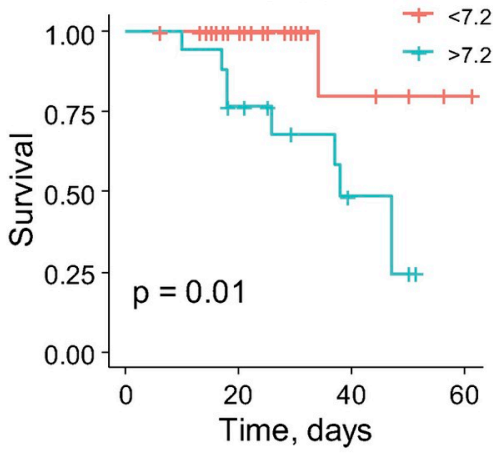

INR

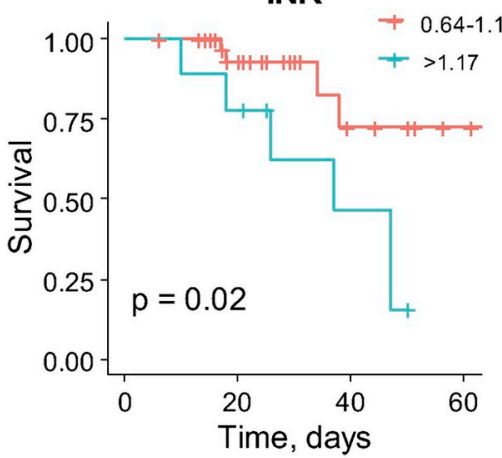

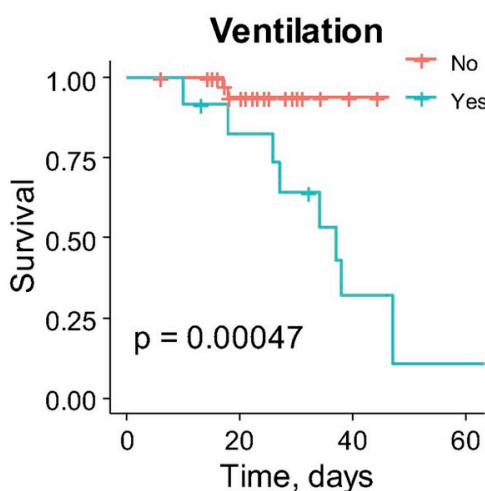

Lymphocyte count

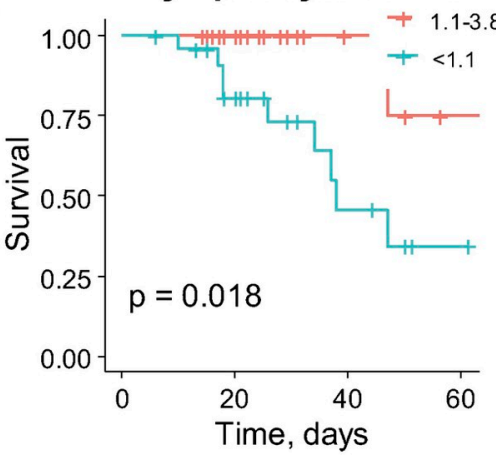

CK
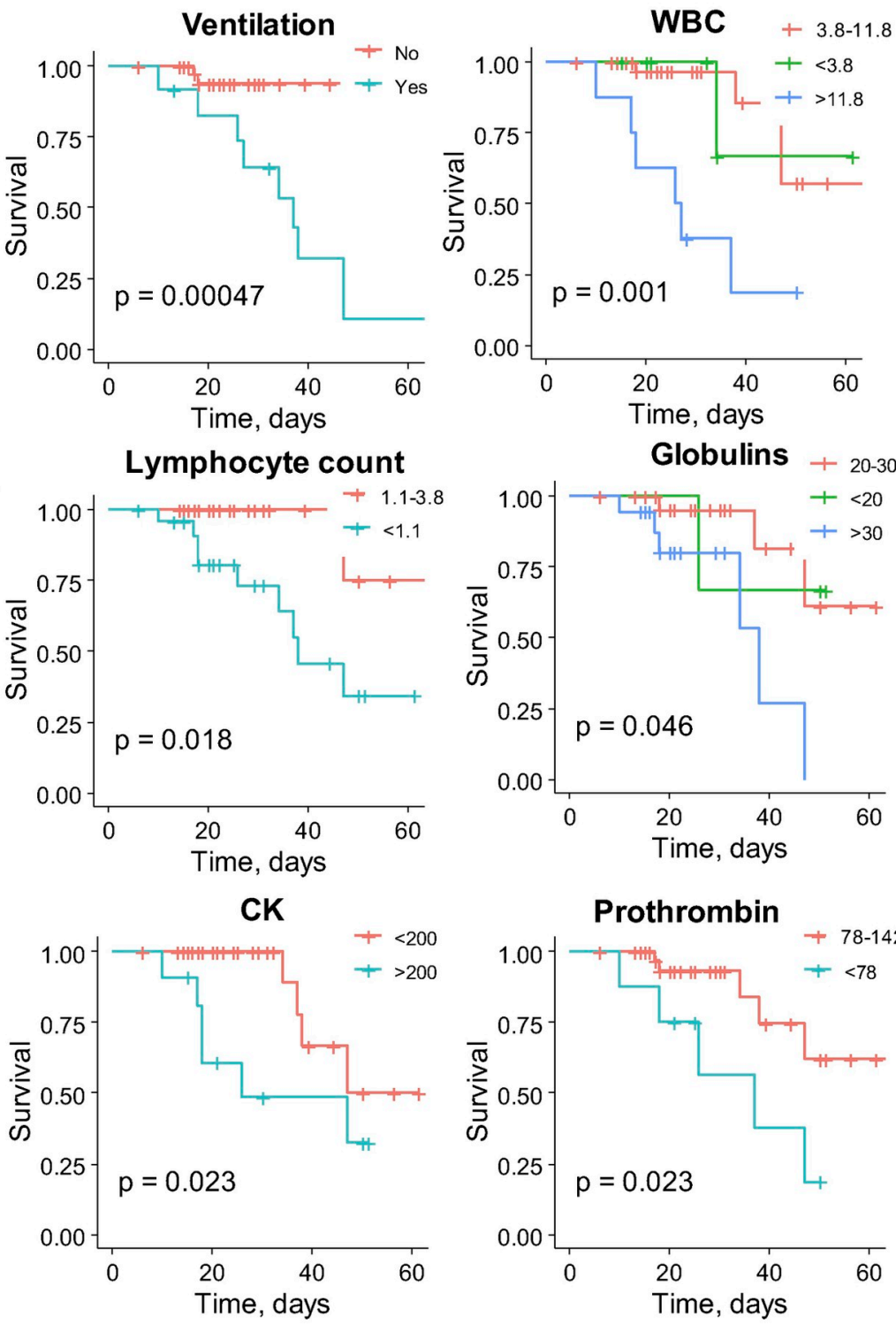

Globulins + 20-30

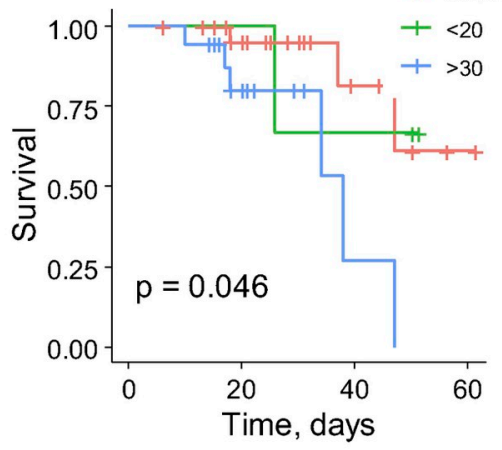

Prothrombin

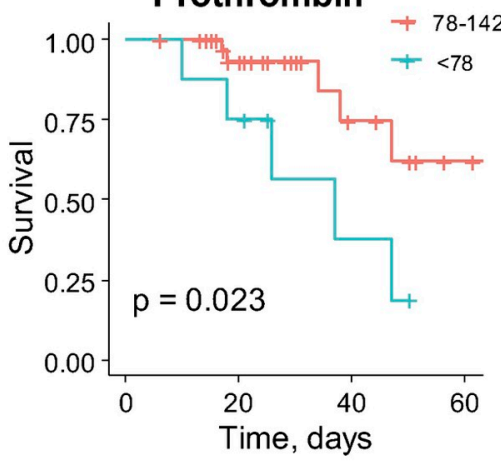

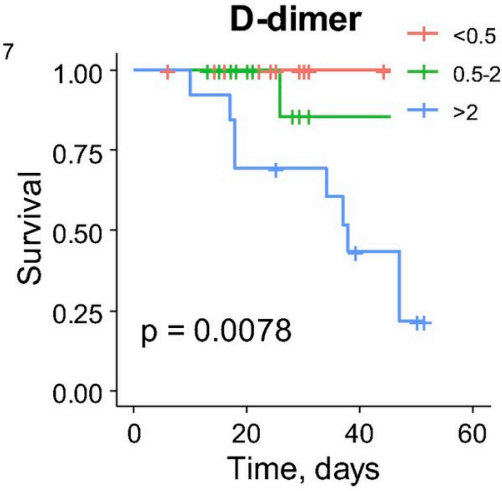

Fig 2. Kaplan-Meier survival curves for patients grouped by clinical and routine blood test parameters. The fraction of survival is expressed on the $\mathrm{y}$-axis, while time (days) of the observation period is expressed on the $\mathrm{x}$-axis. Vertical traits indicate censored data (hospital discharge). $P$ values of log-rank tests are indicated for each graph. Reference group is shown in red.

https://doi.org/10.1371/journal.pone.0264072.g002 


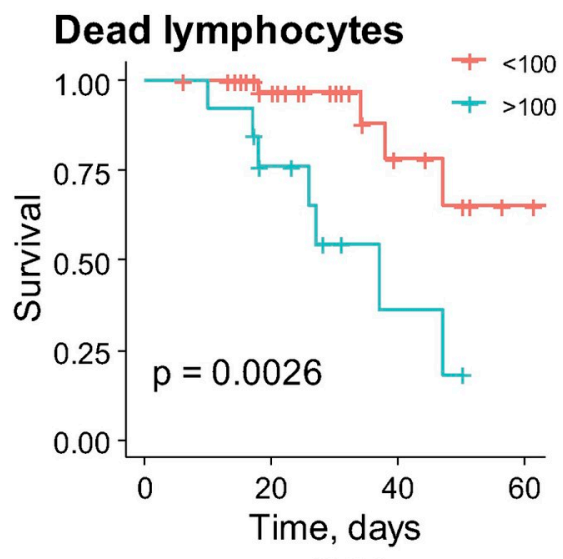

JNK

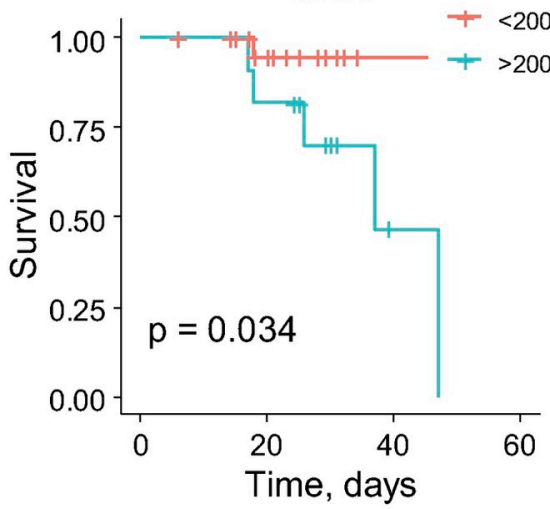

Early apoptosis of lymphocytes CD14+/HLA-Dr+ monocytes
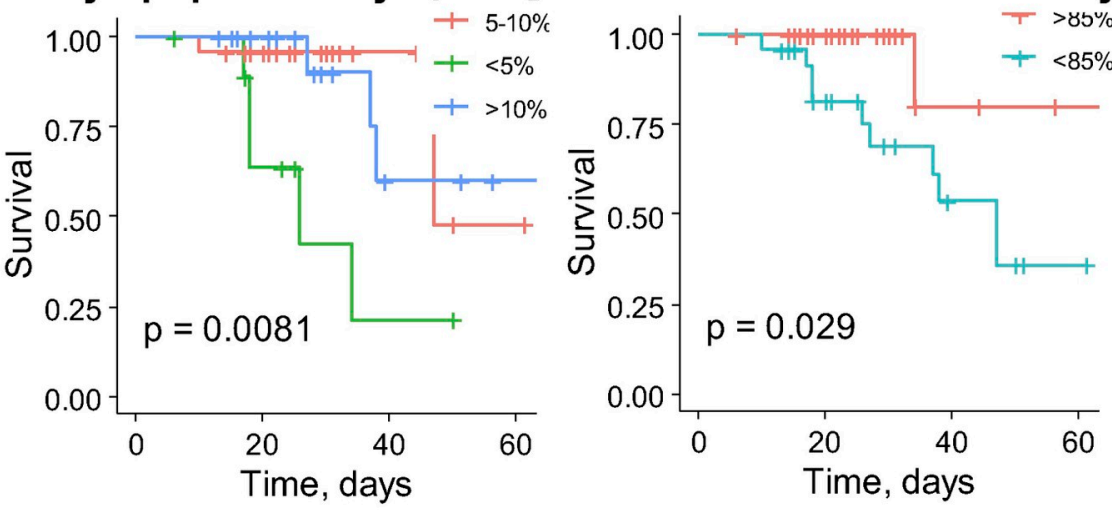

IL17

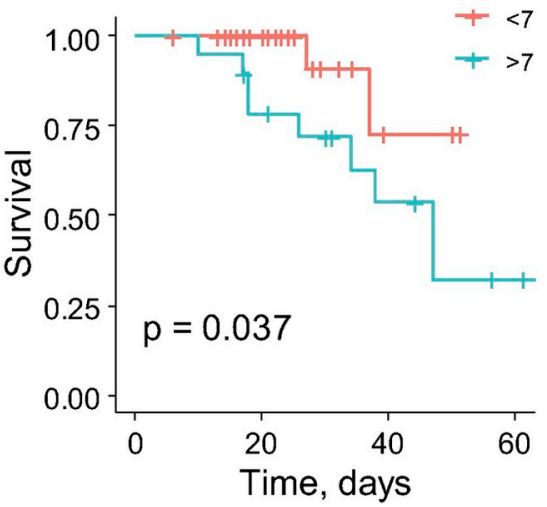

PAl1

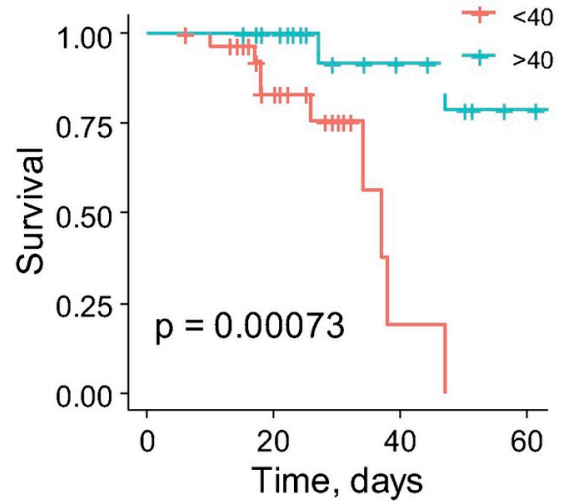

Fig 3. Kaplan-Meier survival curves for patients grouped by biochemical test parameters. The fraction of survival is expressed on the $y$-axis, while time (days) of the observation period is expressed on the $\mathrm{x}$-axis. Vertical traits indicate censored data (hospital discharge). $P$ values of log-rank tests are indicated for each graph. Reference group is shown in red.

https://doi.org/10.1371/journal.pone.0264072.g003

to July 2020 . The overall ICU mortality in this cohort was $21 \%$, which is consistent with previous reports $[15,16]$. Patients from non-survival group had much more severe complications during the hospital stay, including hydrothorax, intoxication, sepsis, multiple organ failure, acute respiratory distress syndrome, which led them eventually to death (Table 1).

To identify prognostic determinants of COVID-19-related mortality, we first assessed classical clinical and routine blood test parameters (Fig 2 and S2 Fig). Chest CT imaging has been recognized to play a pivotal role in monitoring COVID-19 disease progression and predicting adverse prognosis. We found that CT score 3-4 at admission and pulmonary ventilation significantly increase the risk of COVID-19-related death over time (Fig 2) that is in accordance with the previously published data $[2,17-22]$.

A compelling body of evidence indicate that clinical and routine blood test factors such as an increased WBC count [2, 23-30], elevated neutrophil count [2, 24-31], low lymphocyte count $[2,4,17,25,26,28-30]$ are statistically significant and strongly correlate with the adverse outcome in COVID-19 patients. Previously, neutrophil-lymphocyte ratio (NLR) was shown to be a prognostic marker of systemic inflammation in various pathological conditions [32, 33]. Moreover, NLR was found to have a high prognostic value in COVID-19 patients with the increase in neutrophils and the decrease in the total number of lymphocytes in the peripheral blood. Generally, the COVID-19 patients with increased NLR have a poor prognosis and a high risk of death [34]. Our data are in line with recently published papers: we found that the risk of COVID-19-related death over time was significantly increased in patients with elevated 
Table 2. Multivariable Cox proportional hazards survival analysis models for 3 groups of prognostic factors.

\begin{tabular}{|c|c|c|}
\hline Parameter & HR (95\% CI) & $P$ value \\
\hline \multicolumn{3}{|c|}{ Clinical characteristics and hematology results } \\
\hline CT & $0-2$ : reference 3-4: $0.52(0.03-7.85)$ & 0.634 \\
\hline Ventilation & No: reference Yes: 55.66 (2.23-1388.40) & $0.014^{*}$ \\
\hline WBC, $10^{3} / \mu 1$ & $0.58(0.11-2.96)$ & 0.509 \\
\hline Neutrophil count, $10^{3} / \mu \mathrm{l}$ & $2.68(0.57-12.48)$ & 0.210 \\
\hline Lymphocyte count, $10^{3} / \mu \mathrm{l}$ & $0.29(0.01-6.93)$ & 0.447 \\
\hline Monocyte count, $10^{3} / \mu \mathrm{l}$ & $0.15(0.00-1564.4)$ & 0.692 \\
\hline Platelet count, $10^{3} / \mu \mathrm{l}$ & $1.01(1.002-1.027)$ & $0.017^{*}$ \\
\hline \multicolumn{3}{|c|}{ Clinical biochemical routine blood test results } \\
\hline Globulins, g/l & $1.32(1.03-1.70)$ & $0.026 *$ \\
\hline Urea, mM & $0.88(0.62-1.20)$ & 0.467 \\
\hline Creatinine, $\mu \mathrm{M}$ & $1.02(0.99-1.10)$ & 0.244 \\
\hline $\mathrm{ALT}, \mathrm{U} / \mathrm{l}$ & $0.99(0.93-1.00)$ & 0.638 \\
\hline AST, U/l & $1.01(0.98-1.00)$ & 0.572 \\
\hline $\mathrm{LDH}, \mathrm{U} / 1$ & $0.99(0.985-1.00)$ & 0.705 \\
\hline $\mathrm{CK}, \mathrm{U} / \mathrm{l}$ & $1.02(1.005-1.04)$ & $0.013 *$ \\
\hline D-dimer, mg/l & $3.41(1.11-10.50)$ & $0.033^{*}$ \\
\hline \multicolumn{3}{|c|}{ Laboratory blood findings } \\
\hline Dead lymphocyte count & $1.02(1.00-1.04)$ & 0.054 \\
\hline Early lymphocyte apoptosis & $1.09(0.77-1.55)$ & 0.624 \\
\hline CD14+, HLA-Dr+ monocytes, $\%$ & $0.96(0.91-1.01)$ & 0.108 \\
\hline IL-17, pg/ml & $1.07(1.001-1.14)$ & $0.046^{*}$ \\
\hline $\mathrm{IL}-1 \alpha, \mathrm{pg} / \mathrm{ml}$ & $1.09(0.90-1.31)$ & 0.385 \\
\hline PLG, $\mu \mathrm{g} / \mathrm{ml}$ & $0.66(0.32-1.32)$ & 0.238 \\
\hline PAI- $1, \mathrm{pg} / \mathrm{ml}$ & $0.82(0.69-0.98)$ & $0.026^{*}$ \\
\hline $\mathrm{TNF} \alpha, \mathrm{pg} / \mathrm{ml}$ & $0.90(0.68-1.19)$ & 0.464 \\
\hline TGF $\beta, \mathrm{pg} / \mathrm{ml}$ & $1.00(1.00-2.02)$ & 0.069 \\
\hline $\mathrm{ADP}, \mu \mathrm{g} / \mathrm{ml}$ & $0.56(0.30-1.08)$ & 0.083 \\
\hline
\end{tabular}

HR-hazard ratio, CI-confidence interval, ALT-alanine aminotransferase, AST-aspartate aminotransferase, LDHlactate dehydrogenase (LDH), CK-creatine kinase, PLG-plasminogen, PAI-1 -plasminogen activator inhibitor 1, ADP-adiponectin.

${ }^{*}-P<0.05$.

https://doi.org/10.1371/journal.pone.0264072.t002

WBC and neutrophil count, and decreased lymphocyte count (Fig 2). However, when considering clinical characteristics and hematology test results together, only ventilation and elevated platelet count were found to be independent risk factors for mortality (Table 2).

Clinical biochemical routine blood test results, such as increased urea [2, 23, 27, 29-31, 35], upregulated CK $[2,4,17,26,30]$, and augmented level of serum globulins [31] or immunoglobulins [36] can be also valuable in predicting the mortality in COVID-19 patients. Elevated plasma D-dimer is a well-established prognostic factor for adverse outcome in respiratory diseases and COVID-19 [34, 37, 38]. Our results go along with these previously published data and ascertain that the COVID-19-related death over time is significantly increased in patients with elevated serum levels of globulins, urea, CK, augmented D-dimer and INR, and decreased prothrombin (Fig 2). CK, globulins, and D-dimer were identified as independent risk factors for mortality among the tested routine clinical biochemical results (Table 2). 
A potentially practical prognostic opportunity was proposed by other cellular and biochemical factors, that are not in routine clinical practice, such as the sustained elevated production of IL-6 [2, 4, 17, 23, 24, 26, 27, 29-31, 39], IL-1, IL-2R, IL-8, IL-10 [2, 17, 40] and some other blood circulating factors, whose early evaluation anticipated disease progression and duration of hospital stay of COVID-19 patients [41]. Such interleukins as IL-1 $\beta$, IL-6, IL-17A, TNF $\alpha$, and monocyte chemoattractant peptide (MCP)-1 were identified in patients with severe COVID-19 [42]. Huang et al. [43] demonstrated the upregulated levels of IL-1 $\beta$, IL-6, IL-8, IL17 , interferon $\gamma$ (IFN- $\gamma$ ), TNF $\alpha$ in patients with COVID-19 as compared to healthy donors. The same study revealed increased plasma concentrations of MCP-1 and TNF $\alpha$ in patients with COVID-19 admitted to the ICU. Similarly, Chen and co-authors [6] reported the correlation between high concentrations of plasma IL- 6 and TNF $\alpha$ and the severe course of COVID19. In contrast, in the study by Kang and co-authors these cytokines, including IL-1 $\beta$, IL12p40, and IL-17 were undetectable in patients with severe COVID-19 [44]. Several clinical trials investigating interleukin inhibitors (IL-1 inhibitor anakinra, and IL-6 inhibitors tocilizumab or sarilumab) revealed that IL-1 inhibition, but not IL- 6 inhibition, was associated with a significant reduction of mortality in patients admitted to hospital with COVID-19, ARDS (acute respiratory distress syndrome), and hyperinflammation [45]. That is why we next accessed the association of different cellular and biochemical factors with patient survival (Fig 3 and S3 Fig). In the present study IL- $1 \alpha$, TNF $\alpha$ and TGF $\beta$ were not associated with the statistically significant difference in patient survival (S3 Fig); however, elevated IL-17 and decreased PAI-1 were determined as significant and independent risk factors for COVID-19 related death (Fig 3, Table 2).

IL-17 is a promising target in COVID-19, since it operates upstream of both, IL-1 and IL-6 [46]. Although the pathogenic role of IL-17 has been suggested previously, this cytokine was not detected as a mortality risk factor in COVID-19 patients [42, 46]. MERS-CoV infection was reported to be associated with an increased serum level of IL-17, although its correlation with mortality was not demonstrated [47]. IL-17 polymorphisms are associated with susceptibility and poor prognosis in acute respiratory distress syndrome [48]. Meanwhile, in obese patients with confirmed COVID-19, IL-17 boosts neutrophil recruitment via induction of inflammatory cytokine production by respiratory epithelium, smooth muscle cells and fibroblasts resulting in respiratory dysfunction [42].

PAI-1 is a well-known inhibitor of the plasminogen activators (tissue plasminogen activator-tPA, and urokinase-uPA) and hence the overall fibrinolysis [49]. Of note, PAI-1 levels are increased in hypertension, obesity, diabetes, cardiovascular diseases, and old age, which is consistent with the scenario of COVID-19 disease [50, 51]. Plasmin, and other proteases, may cleave the furin site in the $\mathrm{S}$ protein of SARS-CoV-2, thus increasing the virus virulence. Moreover, the dysregulation in fibrinolytic homeostasis in COVID-19 patients with excessive fibrin degradation may result in an unbalanced fibrinolysis inducing multiple organ hemorrhage $[52,53]$. Hyperfibrinolysis resulting from excessive plasmin activity is also associated with elevated D-dimer in severely-ill COVID- 19 patients. While Umemura et al. reported an unchanged PAI-1 level in COVID-19 patients [54], several other groups detected the increased levels of PAI-1, tPA and uPA in COVID-19 patients as compared to heathy controls [55, 56]. Zou and co-authors demonstrated that high levels of tPA and PAI-1 were associated with worse respiratory status in patients hospitalized with COVID-19 [50]. It has been found that overproduced PAI-1 binds to specific receptors on macrophages and upregulates the production of proinflammatory cytokines and chemokines, which further activate the innate immune cells within the infected lungs resulting in lung damage. In turn, high hypoxic environment additionally stimulates PAI-1 production creating a vicious cycle of cytokine storm generated during SARS virus pathogenesis [53]. In contrast, our data indicate that COVID-19-related 
mortality is associated with decreased PAI-1 (Fig 3), establishing that PAI-1 being the constituent component of the fibrinolytic system plays an important role in COVID-19 pathogenesis. The explanation for the reduced PAI- 1 content in the critically-ill patients may reside in compensation for the hyperactivation of plasminogen activator system, reflecting the exhaustion of plasmin inhibitors.

Earlier, it has been demonstrated that COVID-19 patients with severe respiratory failure exhibit low HLA-Dr expression on CD14+ monocytes relative to that of mild COVID-19 patients or healthy volunteers $[57,58]$. Xu and co-authors hypothesized that monocytes in severe COVID-19 displayed a phenotype similar to immunosuppressive monocytic myeloidderived suppressor cells (CD14+/HLA-DR-/lo) [58]. Interestingly, the expression of HLA-Dr on monocytes from healthy donors decreased following the cultivation in media with plasma from patients with COVID-19 who have immune dysregulation [59]. We have defined that the decrease in CD14+/HLA-Dr+ monocyte fraction is associated with mortality in COVID-19 patients (Fig 3).

We also assessed the association of lymphocyte apoptosis with patient survival. The biological role of lymphocyte apoptosis in infectious disease is ambiguous; whether it operates as an intrinsic protective mechanism or mediates a severe course of the disease still remains unclear. Lymphocytes can undergo extensive and ostensibly out-of-control apoptosis during severe infections, potentially contributing to immunosuppression [60]. In the majority of viral infections, lymphocytes are subjected to apoptosis, which is considered to be a defense mechanism preventing the spread of infection without a local inflammatory reaction [61]. Although lymphocyte count can be initially augmented at the onset of COVID-19, its subsequent decline in the course of infection may result in lymphocytopenia and immunodeficiency associated with an increased COVID-19 severity [62]. The frequency of peripheral blood lymphocyte subpopulations, including T-CD4+, T-CD8+, NK, B cells, and monocytes, and their apoptosis pattern was assessed in Iranian COVID-19 patients. The authors reported a marked increase in apoptosis of mononuclear cells from COVID-19 patients as compared to control, however no association with mortality has been addressed in this study [63]. Our data indicate that elevated dead lymphocyte counts are associated with COVID-19 mortality (Fig 3), however, early lymphocyte apoptosis is rather a protective mechanism reflecting the intensity of the adaptive cell immune response to an infectious agent, whereas a decrease in the early apoptosis of lymphocytes is associated with COVID-19-related mortality (Fig 3).

The C-Jun NH2-terminal kinase (JNK1/JNK2) pathway activation ultimately leads to various cellular effects such as inflammatory response, cell proliferation, survival or even apoptosis. JNK signaling pathway was suggested to play a prominent role in immune response to viral infection due to activation of several interleukins (IL-2, IL-4) and IFN- $\gamma$ [64]. To uncover the mechanisms of JNK-mediated inflammation in COVID-19, Shirato and Kizaki carried out an in vitro study and analyzed the effects of SARS-CoV-2 spike protein S1 subunit on murine and human macrophages. Exposure to S1 subunit activated pro-inflammatory mediators (nuclear factor- $\mathrm{\kappa B}(\mathrm{NF}-\mathrm{\kappa B})$ and JNK) signaling pathways via the activation of a toll-like receptor 4 (TLR4) on macrophage surface. Pro-inflammatory cytokine (TNF $\alpha$, IL-6, IL-1 $\beta$, and nitric oxide) production induced by $\mathrm{S} 1$ was abrogated by specific inhibitors of NF- $\mathrm{KB}$ and JNK pathways [65]. In line with the suggested strategy for inhibition of JNK pathway in COVID-19 critically-ill patients as a promising therapeutic approach [66], here we present the first clinical study revealing the increased JNK expression in PBMCs to be a significantly associated with COVID-19-related mortality (Fig 3). It is tempting to speculate that the elevated JNK, which has been demonstrated to induce TLR4-mediated apoptosis in various types of cells [65, 67], and the decreased level of lymphocyte early apoptosis in severe COVID-19 patients revealed in the present study are intertwined. However, this assumption needs further investigation. 
Towards that end, non-routine biochemical test results determined IL-17 and PAI- 1 as independent prognostic factors for COVID-19 related death among others (Table 2), underlying their potential significance as predictors of mortality for patients with COVID-19.

\section{Conclusions}

In conclusion, this study unveiled an integrated set of immunological features and new prognostic markers of patients with severe COVID-19 that are significant predictors of the related mortality. Routine parameters, such as CT score, ventilation, increased WBC and neutrophil count, elevated serum levels of globulins, urea, CK, D-dimer and INR, in parallel with decreased prothrombin and lymphocyte count are risk factors for COVID-19-related mortality. Extended analysis of factors, non-routinely used in clinical practice, suggests a high risk of COVID-19-related death overtime in patients with elevated dead lymphocyte counts, decreased early apoptosis of lymphocytes, reduced fraction of CD14+/HLA-Dr+ monocytes, increased JNK expression in PBMCs, elevated IL-17 and decreased PAI-1 serum levels (Fig 4). In multivariable comparison, IL-17 and PAI-1 are independent prognostic factors among others. Our analysis revealed novel determinants of a high COVID-19-related death risk overtime that can provide for patient stratification at admission to ICU or point to the potential requirement of a more extensive follow up treatment strategies.

SARS-CoV-2

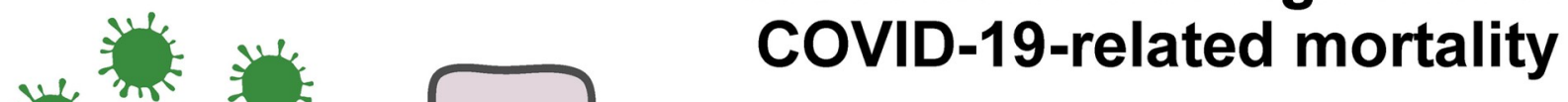

Serum:

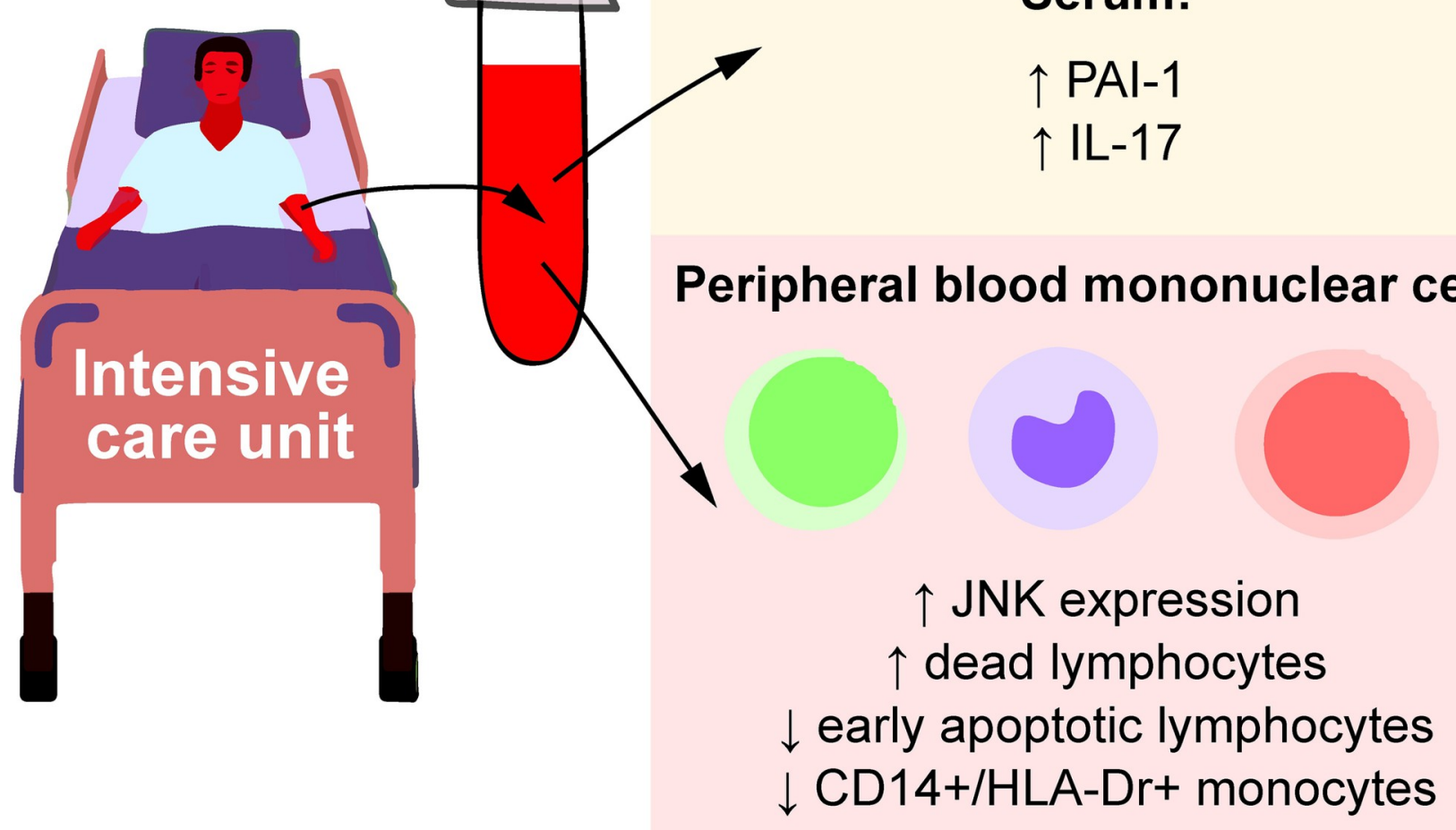

Fig 4. Novel factors that suggest a high risk of COVID-19-related death overtime in patients with severe COVID-19 admitted to ICU.

https://doi.org/10.1371/journal.pone.0264072.g004 
Our study has some limitations. First, the cohort might not be fully representative as the study was a single center one and only the patients admitted to ICU were included. Therefore, a relatively high mortality rate was detected, which cannot reflect the actual COVID-19 mortality in a population. Second, our results might be limited by the sample size. Third, the outcomes were evaluated at the end of the follow-up period instead of a fixed time period during the course of the disease. Fourth, not all laboratory tests were done in all patients, however, the data were missing completely at random. Hence, the interpretation of our results might be limited.

However, we believe that our study uncovers some important tendencies that should be further considered with the relation to COVID-19 mortality. As far as we are aware, this is the first retrospective cohort study among patients with COVID-19 in Russia that evaluated the biochemical parameters in blood serum different from those that are routinely used in healthcare practice. The obtained results may provide a rationale for testing these new parameters as novel markers of COVID-19 severity and point to potential targets for therapeutical intervention in quest to improve the outcomes.

\section{Supporting information}

S1 Table. The accepted reference values of the routine blood tests parameters. (DOCX)

S2 Table. Categorization of biochemical parameters. Reference group is highlighted in bold. MFI-Median Fluorescence Intensity. (DOCX)

S3 Table. Univariable Cox proportional hazards survival analysis models. HR-hazard ratio, CI-confidence interval, Inf-infinite. ${ }^{*}-P<0.05,{ }^{*}-P<0.01$. (DOCX)

S1 Fig. The flow cytometry analysis. A-Representative flow cytometry graphs showing the gating strategy used to assess lymphocyte apoptosis. Forward scatter (FSC) vs. side scatter (SSC) plot applied to gate the lymphocyte cell population and remove the debris. AnnexinFITC-channel vs. 7AAD-channel plot used to gate early (Annexin V+/7AAD-) and late (Annexin $\mathrm{V}+/ 7 \mathrm{AAD}+$ ) apoptotic cells in lymphocyte population. B-Representative flow cytometry graphs showing the gating strategy used to evaluate the percentage of CD14 +/HLA-Dr+ cells in monocyte cell population from the whole blood. Isotypic non-immune IgG (IgG1 Mouse-FITC Isotype Control, A07795, Beckman Coulter) was applied as a control. (TIF)

S2 Fig. Kaplan-Meier survival curves for demographic, other clinical and routine blood test parameters. The fraction of survival is expressed on the $y$-axis, while time (days) of the observation period is expressed on the $\mathrm{x}$-axis. Vertical traits indicate censored data (hospital discharge). $P$ values of log-rank tests are indicated for each graph. Reference group is shown in red.

S3 Fig. Kaplan-Meier survival curves for other biochemical test parameters. The fraction of survival is expressed on the $y$-axis, while time (days) of the observation period is expressed on the $\mathrm{x}$-axis. Vertical traits indicate censored data (hospital discharge). $P$ values of log-rank tests are indicated for each graph. Reference group is shown in red.

(TIF) 


\section{Author Contributions}

Conceptualization: Kseniya Rubina, Anatoliy Evseev, Konstantin Popugaev, Sergey Petrikov.

Data curation: Anna Shmakova, Aslan Shabanov, Yulii Andreev, Natalia Borovkova, Vladimir Kulabukhov, Anatoliy Evseev, Konstantin Popugaev, Ekaterina Semina.

Investigation: Aslan Shabanov, Yulii Andreev, Natalia Borovkova, Vladimir Kulabukhov, Anatoliy Evseev, Konstantin Popugaev, Sergey Petrikov.

Methodology: Anna Shmakova, Aslan Shabanov, Yulii Andreev, Natalia Borovkova, Vladimir Kulabukhov, Anatoliy Evseev, Konstantin Popugaev.

Resources: Aslan Shabanov, Yulii Andreev, Vladimir Kulabukhov.

Software: Anna Shmakova.

Supervision: Kseniya Rubina, Sergey Petrikov, Ekaterina Semina.

Validation: Ekaterina Semina.

Writing - original draft: Kseniya Rubina.

Writing - review \& editing: Kseniya Rubina, Ekaterina Semina.

\section{References}

1. WHO. Coronavirus Disease (COVID-19) Situation Reports. 2021. Available: https://www.who.int/ emergencies/diseases/novel-coronavirus-2019/situation-reports

2. Wang Y, Lu X, Li Y, Chen H, Chen T, Su N, et al. Clinical course and outcomes of 344 intensive care patients with COVID-19. American Journal of Respiratory and Critical Care Medicine. American Thoracic Society; 2020. pp. 1430-1434. https://doi.org/10.1164/rccm.202003-0736LE

3. Coleman JJ, Manavi K, Marson EJ, Botkai AH, Sapey E. COVID-19: to be or not to be; that is the diagnostic question. Postgraduate medical journal. NLM (Medline); 2020. pp. 392-398. https://doi.org/10. 1136/postgradmedj-2020-137979 PMID: 32522844

4. Zhou F, Yu T, Du R, Fan G, Liu Y, Liu Z, et al. Clinical course and risk factors for mortality of adult inpatients with COVID-19 in Wuhan, China: a retrospective cohort study. Lancet. 2020; 395: 1054-1062. https://doi.org/10.1016/S0140-6736(20)30566-3 PMID: 32171076

5. Williamson EJ, Walker AJ, Bhaskaran K, Bacon S, Bates C, Morton CE, et al. Factors associated with COVID-19-related death using OpenSAFELY. Nature. 2020; 584: 430-436. https://doi.org/10.1038/ s41586-020-2521-4 PMID: 32640463

6. Chen G, Wu D, Guo W, Cao Y, Huang D, Wang H, et al. Clinical and immunological features of severe and moderate coronavirus disease 2019. J Clin Invest. 2020; 130: 2620-2629. https://doi.org/10.1172/ JCl137244 PMID: 32217835

7. Zhang SY, Zhang Q, Casanova JL, Su HC, Abel L, Bastard P, et al. Severe COVID-19 in the young and healthy: monogenic inborn errors of immunity? Nature Reviews Immunology. Nature Research; 2020. pp. 455-456. https://doi.org/10.1038/s41577-020-0373-7 PMID: 32555547

8. Морозов СП, Проценко Н, Сметанина СВ, Андрейченко АE, Амброси ОЕ, Баланюк ЭА, et al. Лучевая диагностика коронавирусной болезни (Covid-19): организация, методология, интерпретация результатов. Версия 2 (17.04.2020). Государственное бюд. ... Moscow: Государственное бюджетное учреждение здравоохранения города Москвы «Научно-практический клинический центр диагностики и телемедицинских технологий Департамента здравоохранения города Москвы»; 2020. Available: https://elibrary.ru/item.asp?id=42735464

9. Kilercik M, Demirelce Ö, Serdar MA, Mikailova P, Serteser M. A new haematocytometric index: Predicting severity and mortality risk value in COVID-19 patients. PLoS One. 2021; 16: e0254073. https://doi. org/10.1371/journal.pone.0254073 PMID: 34351940

10. Rizo-Téllez SA, Méndez-García LA, Flores-Rebollo C, Alba-Flores F, Alcántara-Suárez R, ManjarrezReyna AN, et al. The Neutrophil-to-Monocyte Ratio and Lymphocyte-to-Neutrophil Ratio at Admission Predict In-Hospital Mortality in Mexican Patients with Severe SARS-CoV-2 Infection (Covid-19). Microorganisms. 2020; 8: 1-17. https://doi.org/10.3390/microorganisms8101560 PMID: 33050487 
11. Del Valle DM, Kim-Schulze S, Huang H-H, Beckmann ND, Nirenberg S, Wang B, et al. An inflammatory cytokine signature predicts COVID-19 severity and survival. Nat Med 2020 2610. 2020; 26: 1636-1643. https://doi.org/10.1038/s41591-020-1051-9 PMID: 32839624

12. E M, P T, H J, N DR, NK D, SM H, et al. Increased Serum Levels of Soluble TNF- $\alpha$ Receptor Is Associated With ICU Mortality in COVID-19 Patients. Front Immunol. 2021; 12. https://doi.org/10.3389/fimmu. 2021.592727 PMID: 33968010

13. Méry G, Epaulard O, Borel A-L, Toussaint B, Le Gouellec A. COVID-19: Underlying Adipokine Storm and Angiotensin 1-7 Umbrella. Front Immunol. 2020; 0: 1714. https://doi.org/10.3389/fimmu.2020. 01714 PMID: 32793244

14. Kearns SM, Ahern KW, Patrie JT, Horton WB, Harris TE, Kadl A. Reduced adiponectin levels in patients with COVID-19 acute respiratory failure: A case-control study. Physiol Rep. 2021; 9: e14843. https:// doi.org/10.14814/phy2.14843 PMID: 33904656

15. Auld SC, Caridi-Scheible M, Blum JM, Robichaux C, Kraft C, Jacob JT, et al. ICU and Ventilator Mortality Among Critically III Adults With Coronavirus Disease 2019*. Crit Care Med. 2020; 48: e799. https:// doi.org/10.1097/CCM.0000000000004457 PMID: 32452888

16. Oliveira E, Parikh A, Lopez-Ruiz A, Carrilo M, Goldberg J, Cearras M, et al. ICU outcomes and survival in patients with severe COVID-19 in the largest health care system in central Florida. PLoS One. 2021; 16: e0249038. https://doi.org/10.1371/journal.pone.0249038 PMID: 33765049

17. Zhang X-B, Hu L, Ming Q, Wei X-J, Zhang Z-Y, Chen L-D, et al. Risk factors for mortality of coronavirus disease-2019 (COVID-19) patients in two centers of Hubei province, China: A retrospective analysis. Lucas A, editor. PLoS One. 2021; 16: e0246030. https://doi.org/10.1371/journal.pone.0246030 PMID: 33507974

18. Hu Y, Zhan C, Chen C, Ai T, Xia L. Chest CT findings related to mortality of patients with COVID-19: A retrospective case-series study. PLoS One. 2020; 15: e0237302. https://doi.org/10.1371/journal.pone. 0237302 PMID: 32841294

19. Tabatabaei $\mathrm{SMH}$, Rahimi $\mathrm{H}$, Moghaddas $\mathrm{F}$, Rajebi $\mathrm{H}$. Predictive value of $\mathrm{CT}$ in the short-term mortality of Coronavirus Disease 2019 (COVID-19) pneumonia in nonelderly patients: A case-control study. Eur J Radiol. 2020; 132: 109298. https://doi.org/10.1016/j.ejrad.2020.109298 PMID: 32987252

20. Lei $\mathrm{Q}, \mathrm{Li} \mathrm{G}, \mathrm{Ma} X$, Tian J, Wu Y fan, Chen H, et al. Correlation between CT findings and outcomes in 46 patients with coronavirus disease 2019. Sci Rep. 2021; 11: 1103. https://doi.org/10.1038/s41598-02079183-4 PMID: 33441572

21. Li K, Chen D, Chen S, Feng Y, Chang C, Wang Z, et al. Radiographic findings and other predictors in adults with Covid-19. medRxiv. medRxiv; 2020. p. 2020.03.23.20041673. https://doi.org/10.1101/2020. 03.23.20041673

22. Patel U, Malik P, Usman MS, Mehta D, Sharma A, Malik FA, et al. Age-Adjusted Risk Factors Associated with Mortality and Mechanical Ventilation Utilization Amongst COVID-19 Hospitalizations-a Systematic Review and Meta-Analysis. SN Compr Clin Med. 2020; 2: 1740-1749. https://doi.org/10.1007/ s42399-020-00476-w PMID: 32904541

23. Ruan Q, Yang K, Wang W, Jiang L, Song J. Clinical predictors of mortality due to COVID-19 based on an analysis of data of 150 patients from Wuhan, China. Intensive Care Medicine. Springer; 2020. pp. 846-848. https://doi.org/10.1007/s00134-020-05991-x PMID: 32125452

24. Li M, Cheng B, Zeng W, Chen S, Tu M, Wu M, et al. Analysis of the Risk Factors for Mortality in Adult COVID-19 Patients in Wuhan: A Multicenter Study. Front Med. 2020; 7: 545. https://doi.org/10.3389/ fmed.2020.00545 PMID: 32984387

25. Izcovich A, Ragusa MA, Tortosa F, Marzio MAL, Agnoletti C, Bengolea A, et al. Prognostic factors for severity and mortality in patients infected with COVID-19: A systematic review. PLoS One. 2020; 15: e0241955. https://doi.org/10.1371/journal.pone.0241955 PMID: 33201896

26. Huang Y, Lyu X, Li D, Wang L, Wang Y, Zou W, et al. A cohort study of 676 patients indicates D-dimer is a critical risk factor for the mortality of COVID-19. Taylor WR, editor. PLoS One 2020; 15: e0242045. https://doi.org/10.1371/journal.pone.0242045 PMID: 33166991

27. Martins-Filho PR, Tavares CSS, Santos VS. Factors associated with mortality in patients with COVID19. A quantitative evidence synthesis of clinical and laboratory data. European Journal of Internal Medicine. Elsevier B.V.; 2020. pp. 97-99. https://doi.org/10.1016/j.ejim.2020.04.043

28. Ioannou GN, Locke E, Green P, Berry K, O'Hare AM, Shah JA, et al. Risk Factors for Hospitalization, Mechanical Ventilation, or Death Among 10131 US Veterans With SARS-CoV-2 Infection. JAMA Netw open. 2020; 3: e2022310. https://doi.org/10.1001/jamanetworkopen.2020.22310 PMID: 32965502

29. Mesas AE, Cavero-Redondo I, Álvarez-Bueno C, Cabrera MAS, de Andrade SM, Sequí-Dominguez I, et al. Predictors of in-hospital COVID-19 mortality: A comprehensive systematic review and meta-analysis exploring differences by age, sex and health conditions. PLoS One. 2020; 15: e0241742. https://doi. org/10.1371/journal.pone.0241742 PMID: 33141836 
30. Wang L, He W, Yu X, Hu D, Bao M, Liu H, et al. Coronavirus disease 2019 in elderly patients: Characteristics and prognostic factors based on 4-week follow-up. J Infect. 2020; 80: 639-645. https://doi.org/10. 1016/j.jinf.2020.03.019 PMID: 32240670

31. Wu C, Chen X, Cai Y, Xia J, Zhou X, Xu S, et al. Risk Factors Associated with Acute Respiratory Distress Syndrome and Death in Patients with Coronavirus Disease 2019 Pneumonia in Wuhan, China. JAMA Intern Med. 2020; 180: 934-943. https://doi.org/10.1001/jamainternmed.2020.0994 PMID: 32167524

32. Huang H, Wan X, Bai Y, Bian J, Xiong J, Xu Y, et al. Preoperative neutrophil-lymphocyte and plateletlymphocyte ratios as independent predictors of $T$ stages in hilar cholangiocarcinoma. Cancer Manag Res. 2019; 11: 5157-5162. https://doi.org/10.2147/CMAR.S192532 PMID: 31239770

33. Celikbilek M, Dogan S, Ozbakir O, Zararsiz G, Kücük H, Gürsoy S, et al. Neutrophil-Lymphocyte Ratio as a Predictor of Disease Severity in Ulcerative Colitis. J Clin Lab Anal. 2013; 27: 72-76. https://doi.org/ 10.1002/jcla.21564 PMID: 23292894

34. Ye W, Chen G, Li X, Lan X, Ji C, Hou M, et al. Dynamic changes of D-dimer and neutrophil-lymphocyte count ratio as prognostic biomarkers in COVID-19. Respir Res. 2020; 21: 169. https://doi.org/10.1186/ s12931-020-01428-7 PMID: 32620118

35. Cheng A, Hu L, Wang Y, Huang L, Zhao L, Zhang C, et al. Diagnostic performance of initial blood urea nitrogen combined with D-dimer levels for predicting in-hospital mortality in COVID-19 patients. Int J Antimicrob Agents. 2020; 56: 106110. https://doi.org/10.1016/j.ijantimicag.2020.106110 PMID: 32712332

36. Zhao Y, Nie HX, Hu K, Wu XJ, Zhang YT, Wang MM, et al. Abnormal immunity of non-survivors with COVID-19: Predictors for mortality. Infect Dis Poverty. 2020; 9: 108. https://doi.org/10.1186/s40249020-00723-1 PMID: 32746940

37. Ge YL, Liu CH, Wang N, Xu J, Zhu XY, Su CS, et al. Elevated plasma D-dimer in adult communityacquired pneumonia patients is associated with an increased inflammatory reaction and lower survival. Clin Lab. 2019; 65: 131-138. https://doi.org/10.7754/Clin.Lab.2018.180720 PMID: 30775898

38. Fruchter $\mathrm{O}$, Yigla M, Kramer MR. D-dimer as a prognostic biomarker for mortality in chronic obstructive pulmonary disease exacerbation. Am J Med Sci. 2015; 349: 29-35. https://doi.org/10.1097/MAJ. 0000000000000332 PMID: 25233043

39. Mikami T, Miyashita H, Yamada T, Harrington M, Steinberg D, Dunn A, et al. Risk Factors for Mortality in Patients with COVID-19 in New York City. J Gen Intern Med. 2021; 36: 17-26. https://doi.org/10. 1007/s11606-020-05983-z PMID: 32607928

40. Gong J, Dong H, Xia QS, Huang Z yi, Wang D kun, Zhao Y, et al. Correlation analysis between disease severity and inflammation-related parameters in patients with COVID-19: a retrospective study. BMC Infect Dis. 2020; 20. https://doi.org/10.1186/s12879-020-05681-5 PMID: 33349241

41. Laing AG, Lorenc A, del Molino del Barrio I, Das A, Fish M, Monin L, et al. A dynamic COVID-19 immune signature includes associations with poor prognosis. Nat Med. 2020; 26: 1623-1635. https://doi.org/10. 1038/s41591-020-1038-6 PMID: 32807934

42. Leija-Martínez JJ, Huang F, Del-Río-Navarro BE, Sanchéz-Muñoz F, Muñoz-Hernández O, GiacomanMartínez A, et al. IL-17A and TNF- $\alpha$ as potential biomarkers for acute respiratory distress syndrome and mortality in patients with obesity and COVID-19. Med Hypotheses. 2020; 144: 109935. https://doi. org/10.1016/j.mehy.2020.109935 PMID: 32795834

43. Huang C, Wang Y, Li X, Ren L, Zhao J, Hu Y, et al. Clinical features of patients infected with 2019 novel coronavirus in Wuhan, China. Lancet. 2020; 395: 497-506. https://doi.org/10.1016/S0140-6736(20) 30183-5 PMID: 31986264

44. Kang S, Tanaka T, Inoue H, Ono C, Hashimoto S, Kioi Y, et al. IL-6 trans-signaling induces plasminogen activator inhibitor- 1 from vascular endothelial cells in cytokine release syndrome. Proc Natl Acad Sci U S A. 2020; 117: 22351-22356. https://doi.org/10.1073/pnas.2010229117 PMID: 32826331

45. Cron RQ. COVID-19 cytokine storm: targeting the appropriate cytokine. Lancet Rheumatol. 2021; 3 : E236-E237. https://doi.org/10.1016/S2665-9913(21)00011-4 PMID: 33655221

46. Pacha O, Sallman MA, Evans SE. COVID-19: a case for inhibiting IL-17? Nature Reviews Immunology. Nature Research; 2020. pp. 345-346. https://doi.org/10.1038/s41577-020-0328-z PMID: 32358580

47. Mahallawi WH, Khabour OF, Zhang Q, Makhdoum HM, Suliman BA. MERS-CoV infection in humans is associated with a pro-inflammatory Th1 and Th17 cytokine profile. Cytokine. 2018; 104: 8-13. https:// doi.org/10.1016/j.cyto.2018.01.025 PMID: 29414327

48. Xie M, Cheng B, Ding Y, Wang C, Chen J. Correlations of IL-17 and NF-kB gene polymorphisms with susceptibility and prognosis in acute respiratory distress syndrome in a Chinese population. Biosci Rep. 2019; 39: BSR20181987. https://doi.org/10.1042/BSR20181987 PMID: 30655311 
49. Eden G, Archinti M, Furlan F, Murphy R, Degryse B. The urokinase receptor interactome. Curr Pharm Des. 2011; 17: 1874-1889. https://doi.org/10.2174/138161211796718215 PMID: 21711237

50. Zuo Y, Warnock M, Harbaugh A, Yalavarthi S, Gockman K, Zuo M, et al. Plasma tissue plasminogen activator and plasminogen activator inhibitor-1 in hospitalized COVID-19 patients. Sci Rep. 2021; 11 : 1580. Available: https://www.nature.com/articles/s41598-020-80010-z https://doi.org/10.1038/s41598020-80010-z PMID: 33452298

51. Cesari M, Pahor M, Incalzi RA. REVIEW: Plasminogen Activator Inhibitor-1 (PAI-1): A Key Factor Linking Fibrinolysis and Age-Related Subclinical and Clinical Conditions. Cardiovasc Ther. 2010; 28: e72e91. https://doi.org/10.1111/j.1755-5922.2010.00171.x PMID: 20626406

52. Ji HL, Zhao R, Matalon S, Matthay MA. Elevated plasmin(Ogen) as a common risk factor for COVID-19 susceptibility. Physiol Rev. 2020; 100: 1065-1075. https://doi.org/10.1152/physrev.00013.2020 PMID: 32216698

53. Matsuyama T, Kubli SP, Yoshinaga SK, Pfeffer K, Mak TW. An aberrant STAT pathway is central to COVID-19. Cell Death and Differentiation. Springer Nature; 2020. pp. 3209-3225. https://doi.org/10. 1038/s41418-020-00633-7 PMID: 33037393

54. Umemura Y, Yamakawa K, Kiguchi T, Nishida T, Kawada M, Fujimi S. Hematological Phenotype of COVID-19-Induced Coagulopathy: Far from Typical Sepsis-Induced Coagulopathy. J Clin Med. 2020; 9: 2875. https://doi.org/10.3390/jcm9092875 PMID: 32899532

55. Cabrera-Garcia D, Miltiades A, Parsons S, Elisman K, Mansouri MT, Wagener G, et al. High levels of plasminogen activator inhibitor-1, tissue plasminogen activator and fibrinogen in patients with severe COVID-19. medRxiv. 2021; 2020.12.29.20248869. https://doi.org/10.1101/2020.12.29.20248869

56. Cugno M, Meroni PL, Gualtierotti R, Griffini S, Grovetti E, Torri A, et al. Complement activation and endothelial perturbation parallel COVID-19 severity and activity. J Autoimmun. 2021; 116: 102560. https://doi.org/10.1016/j.jaut.2020.102560 PMID: 33139116

57. Giamarellos-Bourboulis EJ, Netea MG, Rovina N, Akinosoglou K, Antoniadou A, Antonakos N, et al. Complex Immune Dysregulation in COVID-19 Patients with Severe Respiratory Failure. Cell Host Microbe. 2020; 27: 992-1000.e3. https://doi.org/10.1016/j.chom.2020.04.009 PMID: 32320677

58. Xu G, Qi F, Li H, Yang Q, Wang H, Wang X, et al. The differential immune responses to COVID-19 in peripheral and lung revealed by single-cell RNA sequencing. Cell Discov. 2020; 6: 1-14. https://doi.org/ 10.1038/s41421-019-0132-8 PMID: 31934347

59. Dempsey LA. Immune dysregulation. Nat Immunol. 2020; 21: 596. https://doi.org/10.1038/s41590-0200702-9 PMID: 32457531

60. Parrino J, Hotchkiss RS, Bray M. Prevention of immune cell apoptosis as potential therapeutic strategy for severe infections. Emerging Infectious Diseases. Centers for Disease Control and Prevention (CDC); 2007. pp. 191-198. https://doi.org/10.3201/eid1302.060963 PMID: 17479879

61. Somova LM, Besednova NN, Plekhova NG. Apoptosis and infectious diseases. Russ J Infect Immun. 2015; 4: 303-318. https://doi.org/10.15789/2220-7619-2014-4-303-318

62. Fathi N, Rezaei N. Lymphopenia in COVID-19: Therapeutic opportunities. Cell Biol Int. 2020; 44: 17921797. https://doi.org/10.1002/cbin.11403 PMID: 32458561

63. Taghiloo S, Aliyali M, Abedi S, Mehravaran H, Sharifpour A, Zaboli E, et al. Apoptosis and immunophenotyping of peripheral blood lymphocytes in Iranian COVID-19 patients: Clinical and laboratory characteristics. J Med Virol. 2021; 93: 1589-1598. https://doi.org/10.1002/jmv.26505 PMID: 32910458

64. Hemmat N, Asadzadeh Z, Ahangar NK, Alemohammad H, Najafzadeh B, Derakhshani A, et al. The roles of signaling pathways in SARS-CoV-2 infection; lessons learned from SARS-CoV and MERSCoV. Archives of Virology. Springer; 2021. pp. 675-696. https://doi.org/10.1007/s00705-021-04958-7 PMID: 33462671

65. Shirato K, Kizaki T. SARS-CoV-2 spike protein S1 subunit induces pro-inflammatory responses via tolllike receptor 4 signaling in murine and human macrophages. Heliyon. 2021; 7: e06187. https://doi.org/ 10.1016/j.heliyon.2021.e06187 PMID: 33644468

66. Solimani F, Meier K, Ghoreschi K. Janus kinase signaling as risk factor and therapeutic target for severe SARS-CoV-2 infection. Eur J Immunol. 2021; eji.202149173. https://doi.org/10.1002/eji.202149173 PMID: 33675065

67. Zhang Y, Bliska JB. Role of toll-like receptor signaling in the apoptotic response of macrophages to Yersinia infection. Infect Immun. 2003; 71: 1513-1519. https://doi.org/10.1128/IAI.71.3.1513-1519.2003 PMID: 12595470 